\title{
Impact of Co-administered Lopinavir/Ritonavir and Sulfamethoxazole/Trimethoprim on Reproductive Indices of Male Albino Rats
}

\author{
Deo Oputiri ${ }^{1}$, and Adikwu Elias ${ }^{2, *}$ \\ ${ }^{1}$ Department of Pharm Tech, College of Health Technology, Otuogidi, Ogbia, L. G. A., Bayelsa State \\ ${ }^{2}$ Department of Pharmacology, Faculty of Basic Medical Sciences, College of Health Sciences, University of Port Harcourt, Choba, \\ Rivers State, Nigeria \\ *Corresponding author: adikwuelias@gmail.com
}

\begin{abstract}
Antiretroviral drugs containing Lopinavir/ ritonavir (LPV/r) are usually co-administered with sulfamethoxazole / trimethoprim (SMX/TMP) in the management of HIV/AIDS and co infections. The concurrent use of these drugs may place more adverse burden on testicular function because reports have associated these drugs individually with decreased testicular function. This study therefore evaluated the effects of the co-administration of SMX/TMP + LPV/r on reproductive indices of male albino rats. Eighty (80) adult male rats which were divided into five (5) groups A-E were used in this study. Animals in group A which served as the control were treated with $1 \%$ ethanol while animals in groups B-E were treated orally with SMX/TMP, $(22.4 / 4.6 \mathrm{mg} / \mathrm{kg}), \mathrm{LPV} / \mathrm{r}(22.8 / 5.8 \mathrm{mg} / \mathrm{kg})$ and combined doses of SMX/TMP + LPV/r for 2-8 weeks respectively. Animals were sacrificed at the end of treatment, testes were collected and weighed. Sperm count, sperm motility, and morphology were evaluated. Testicular levels of malondialdehyde (MDA), super oxide dismutase (SOD) and histopathological changes were also analyzed. Single doses of LPV/r and SMX/TMP produced significant time dependent decrease in total sperm count and sperm motility, with increase in abnormal sperm morphology. Treatment with single doses of these agents time dependently increased testicular MDA, decreased SOD level and induced abnormal testicular histopathological changes. No significant synergistic effects were observed in all evaluated parameters when these agents were coadministered. Conclusion: Due to lack of significant synergistic effects on all evaluated parameters with the coadministration of these agents, the concurrent use of these agents in the management of HIV and co- infections may not have any deleterious effect on male reproductive function.
\end{abstract}

Keywords: testis, toxicity, sulfamethoxazole/trimethoprim, lopinavir/ritonavir, rats

Cite This Article: Deo Oputiri, and Adikwu Elias, "Impact of Co-administered Lopinavir/Ritonavir and Sulfamethoxazole/Trimethoprim on Reproductive Indices of Male Albino Rats." American Journal of Pharmacological Sciences, vol. 2, no. 5 (2014): 93-99. doi: 10.12691/ajps-2-5-4.

\section{Introduction}

Infertility is defined as the inability to achieve pregnancy after one year of unprotected intercourse [1]. Infertility is reported to be on the increase over the past decade due to the number of couples seeking consultation for infertility problems with about $50 \%$ attributed to male factors [2,3]. Infertility among males could be basically diagnosed through semen analysis which involves the evaluation of sperm count, sperm motility, and sperm morphology $[4,5,6,7]$. Quite a number of factors have been reported to be actively associated with infertility. Among them are pharmaceutical medications as well as recreational drugs which have been shown to affect fertility through decreased ejaculation, induction of erectile dysfunction and decreased libido by impacting seriously on testicular function and structure $[8,9,10,11]$.

Lopinavir/Ritonavir and sulfamethoxazole/trimethoprim are antimicrobial agents used in the management of
HIV/AIDS and co-infections. Lopinavir is usually boosted with ritonavir to increase its pharmacological profile. In the management of HIV/AIDS lopinavir/ritonavir is used as a combination therapy with other antiretroviral drugs $[12,13,14,15]$. Lopinavir/ritonavir mediates its antiviral activity by binding the protease enzyme, and preventing the cleavage of the gag and gag/pol polyproteins into structural functional proteins and enzymes thereby preventing the formation of new viral particles [16]. Sulfamethoxazole/trimethoprim mediates its action by causing sequential blockade of the various steps involved in microbial folate synthesis, which is necessary for the formation of purines and, ultimately, of DNA $[17,18]$.

As a result of HIV/AIDS associated co-morbidity and coinfection the concurrent use of antiretroviral and antibacterial drugs is inevitable and in some cases antiretroviral drugs containig lopinavir/ritonavir are concurrently used with sulfamethoxazole/trimethoprim [19,20]. The concurrent use of these drugs may place more toxicological burden on male reproductive function because reports have 
associated these drugs individually with decreased testicular function [21,22,23,24] but with no literature on the possible toxicological interaction of the co-administration of these agents on male reproductive function. This study therefore, evaluated the possible effects of co-administered lopinavir/ritonavir and sulfamethoxazole/trimethoprim on reproductive indices of male albino rats.

\section{Materials and Methods}

Drugs: Lopinavir/ritonavir (LPV/r) used in this work was manufactured by Myland Laboratories Limited India. Other ingredients in the LPV/r tablet include colloidal silicon dioxide, copovidone, sodium stearyl fumarate and sorbitan monolaurate. Sulfamethoxazole/Trimethoprim (SMX/TMP) used in this study was manufactured by CSPC Ouyi Pharmaceuticals China. Other ingredients in SMX/TMP tablets include magnesium stearate, maize starch, silica and sodium lauryl sulphate.

Animals: The animals used in this research work were obtained from the animal house of the Department of Pharmacology and Toxicology, Madonna University, Elele, Rivers State. The animals were allowed free access to food and water ad libitum and were allowed to acclimatize for 14 days. Animals were handled according to Helsinki declaration on the handling and use of animals.

Dose Selection: $22.4 / 4.6 \mathrm{mg} / \mathrm{kg}$ of sulfamethoxazole/ trimethoprim and $22.8 / 5.8 \mathrm{mg} / \mathrm{kg}$ of Lopinavir/ritonavir were used in this study [25,26].

\subsection{Preparation of Drug}

Lopinavir/ritonavir tablets were crushed and dissolved in $1 \%$ ethanol while sulfamethoxazole/ trimethoprim tablets were crushed and suspended in water [27].

\subsection{Grouping of Animals}

Eighty (80) healthy male albino rats of average weight $300 \mathrm{~g} \pm 5$ were used in this study. The rats were housed in a large mesh cage and divided into five groups A - E.

\subsection{Drug Administration}

Group A: This served as the control and contained twenty (20) animals which were treated with $1 \%$ ethanol orally throughout the duration of study.

Group B: This group contained 15 animals which were further divided into 3 subgroups (B1-B3). Animals in group B1 were treated with $22.4 / 4.6 \mathrm{mg} / \mathrm{kg}$ of SMX/TMP. Animals in group B2 were treated with $22.8 / 5.8 \mathrm{mg} / \mathrm{kg}$ of LPV/r. Animals in group B3 were treated with combined doses of SMX/TMP + LPV/r. All animals in this group were treated for 2 weeks

Group C: This group contained 15 animals which were further divided into 3 subgroups (C1-C3). Animals in group C1 were treated with $22.4 / 4.6 \mathrm{mg} / \mathrm{kg}$ of SMX/TMP. Animals in group C2 were treated with $22.8 / 5.8 \mathrm{mg} / \mathrm{kg}$ of LPV/r. Animals in group C3 were treated with combined doses of SMX/TMP + LPV/r. All animals in this group were treated for 4 weeks.

Group D: This group contained 15 animals which were further divided into 3 subgroups (D1-D3). Animals in group D1 were treated with $22.4 / 4.6 \mathrm{mg} / \mathrm{kg}$ of SMX/TMP.
Animals in group D2 were treated with $22.8 / 5.8 \mathrm{mg} / \mathrm{kg}$ of $\mathrm{LPV} / \mathrm{r}$. Animals in group D3 were treated with combined doses of SMX/TMP + LPV/r. All animals in this group were treated for 6 weeks.

Group E: This group contained 15 animals which were further divided into 3 subgroups (E1-E3). Animals in group E1 were treated with $22.4 / 4.6 \mathrm{mg} / \mathrm{kg}$ of SMX/TMP. Animals in group E2 were treated with $22.8 / 5.8 \mathrm{mg} / \mathrm{kg}$ of $\mathrm{LPV} / \mathrm{r}$. Animals in group E3 were treated with combined doses of SMX/TMP + LPV/r. All animals in this group were treated for 8 weeks.

\subsection{Collection of Sample for Analysis}

Animals were sacrificed using chloroform anesthesia at the end of 2, 4, 6 and 8 weeks of treatment respectively, the testes were harvested, weighed and analyzed for histopathological changes.

\subsection{Preparation of Tissue Homogenate}

Testicular tissues homogenate was prepared as reported by Nathiya and Nandhini, 2014 [28].

\subsection{Biochemical Evaluations}

\subsubsection{Malondialdehyde and Superoxide Dismutase}

Testes malondialdehyde (MDA) concentrations, a lipid per oxidation index, were determined according to Draper and Hadley, 1990. [29] Superoxide dismutase (SOD) activity was estimated according to Beauchamp and Fridovich [30]

\subsection{Semen Analysis}

\subsubsection{Sperm Count and Sperm Motility}

The epididymal sperm count and sperm motility were evaluated as reported by WHO laboratory manual for the examination of human semen and sperm-cervical mucus interaction [31].

\subsubsection{Sperm Morphology}

Sperm morphology was evaluated according to the method reported by Wyrobek and Bruce, 1975, [32] Narayana et al., 2002 [33].

\subsection{Histopathological Analysis}

Histopathological analysis of the testes was performed using standard laboratory technique [34].

\subsection{Statistical Analysis}

Results were expressed as mean \pm S.E.M. Statistical analysis was done with the aid of SPSS for windows; SPSS Inc., Chicago, Standard version 14.0 to determine difference between mean using one way analysis of variance (ANOVA).

\section{Results}

\subsection{Effects on Testicular Weight, Malondialdehyde and Superoxide Dismutase}


Exposure to single doses of SMX/TMP, LPV/r, and combined doses of SMX/TMP + LPV/r did not produce any significant $(p>0.05)$ change in testicular weight with respect to the control [Table 1]. Treatment with SMX/TMP produced a time dependent increase in MDA level which was significant $(p<0.05)$ at 6 and 8 weeks with respect to the control. Significant $(p<0.05)$ increase in testicular MDA which represents $92.2 \%$ was observed in animals exposed to $\mathrm{LPV} / \mathrm{r}$ at week 8 when compared with the control. Co-administration of SMX/TMP + LPV/r produced a time dependent increase in testicular MDA with significance $(71 \%$ and $139 \% \mathrm{p}<0.05)$ at 6 and 8 weeks when compared with the control [Table 2].

Time dependant decrease in testicular superoxide dismutase level was noted in animals exposed to SMX/TMP which was significant at week 8 with respect to the control [Table 3]. Treatment with $\mathrm{LPV} / \mathrm{r}$ produced time dependent decreases in SOD to $9.83 \pm 2.07,9.52 \pm 1.06$, $6.23 \pm 1.05$ and $5.00 \pm 1.17$ at $2-8$ weeks respectively. These decreases were observed to be significant $(p<0.05)$ at 6 and 8 weeks with respect to the control.[Table 3] Treatment with combined doses of SMX/TMP + LPV/r produced a time dependent decrease in testicular SOD with significance at 6 and 8 weeks when compared with the control [Table 3].

\subsection{Effects on Sperm Count}

Results showed that treatment with SMX/TMP produced a time dependent decrease in sperm count with significance (47\% and $54 \% p<0.05$ ) at week 6 and 8 while treatment with LPV/r produced time dependent decrease in sperm count with significance $(42 \% p<0.05)$ at week 8 with respect to the control. Treatment with combined doses of SMX/TMP + LPV/r produced a significant $(p<0.05)$ time dependent decrease in sperm count at weeks 4,6 and 8 respectively when compared with control [Table 4].

\subsection{Effects on Sperm Motility}

Treatment with SMX/TMP produced a time dependent decrease in sperm motility which was observed to be statistically significant $(p<0.05)$ at week 6 and 8 while treatment with LPV/r decreased sperm motility time dependently with significance $(49 \%, 56 \% \mathrm{p}<0.05)$ at week 6 , and 8 with respect to the control. Results showed that treatment with co- administered SMX/TMP + LPV/r, time dependently and significantly $(p<0.05)$ decreased sperm motility at weeks 6 and 8 respectively, when compared with the control [Table 5].

\subsection{Effects on Sperm Morphology}

Time dependent increase in abnormal sperm morphology which becomes significant $(p<0.05)$ at week 6 and 8 with respect to the control was noted in animals treated with LPV/r while treatment with SMX/TMP produced significant increase $(p<0.05)$ in abnormal sperm morphology at week 8 with respect to the control. Combined doses of these agents produced time dependant increase in abnormal sperm morphology with significance at week 6 and 8 when compared with the control [Table 6].

\subsection{Effects on Histopathology of the Testes}

The control testes of rats treated with $1 \%$ ethanol showed normal seminiferous tubules and maturation stages of spermatocytes [Photomicrograph A]. Testes of rats treated with $22.4 / 4.6 \mathrm{mg} / \mathrm{kg}$ of SMX/TMP for 8 weeks showed normal seminiferous tubules but with mildly widened interstitium by edema fluid [Photomicrograph B]. Testes of rats treated with $22.8 / 5.8 \mathrm{mg} / \mathrm{kg}$ of $\mathrm{LPV} / \mathrm{r}$ for 8 weeks revealed thick basement membrane of the seminiferous tubules with loss of maturation stages of spermatocytes and focal cytolysis [Photomicrograph C]. The testes of rats treated with combined doses of SMX/TMP + LPV/r for 8 weeks showed thick basement membrane of the seminiferous tubules with loss of maturation stages of spermatocytes, focal cytolysis and edematous interstitium infiltrated by mononuclear inflammatory cells [Photomicrograph D].

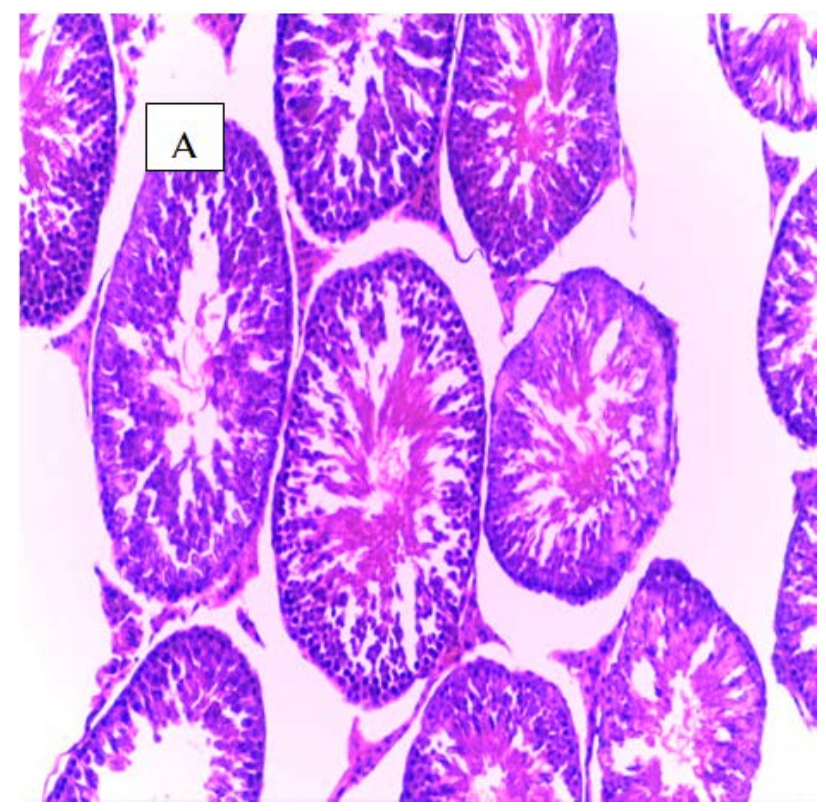

Photomicrograph A. The control testis of rat treated with $1 \%$ ethanol showing normal seminiferous tubules and maturation stages of spermatocytes (H\&E x400)

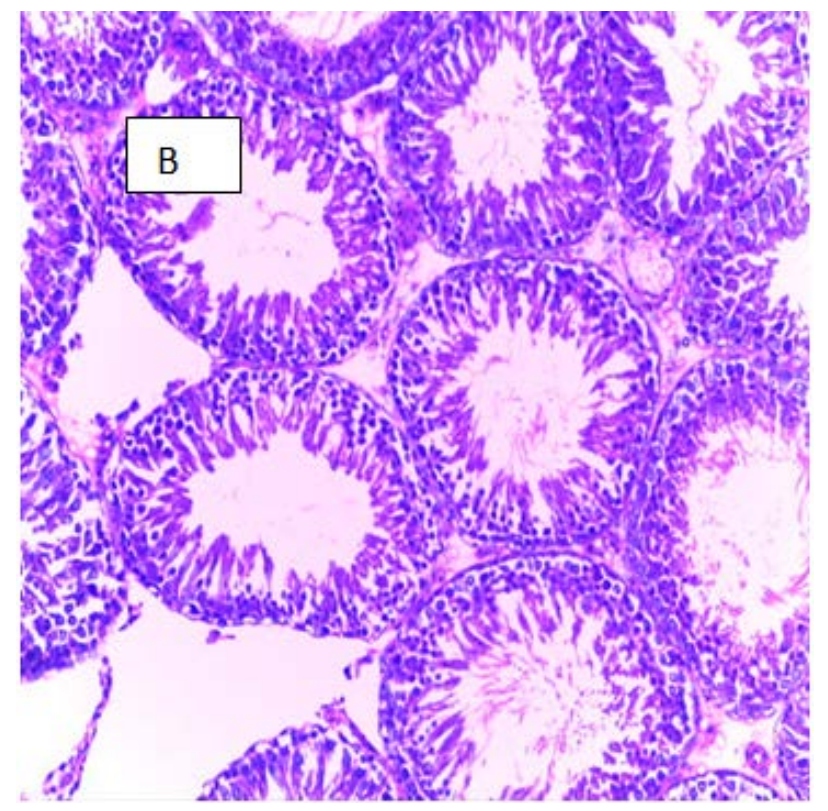

Photomicrograph B. The testis of rat treated with $22.4 / 4.6 \mathrm{mg} / \mathrm{kg}$ of SMX/TMP for 8 weeks showing normal seminiferous tubules but with mildly widened interstitium by edema fluid. (H\&E x 400) 


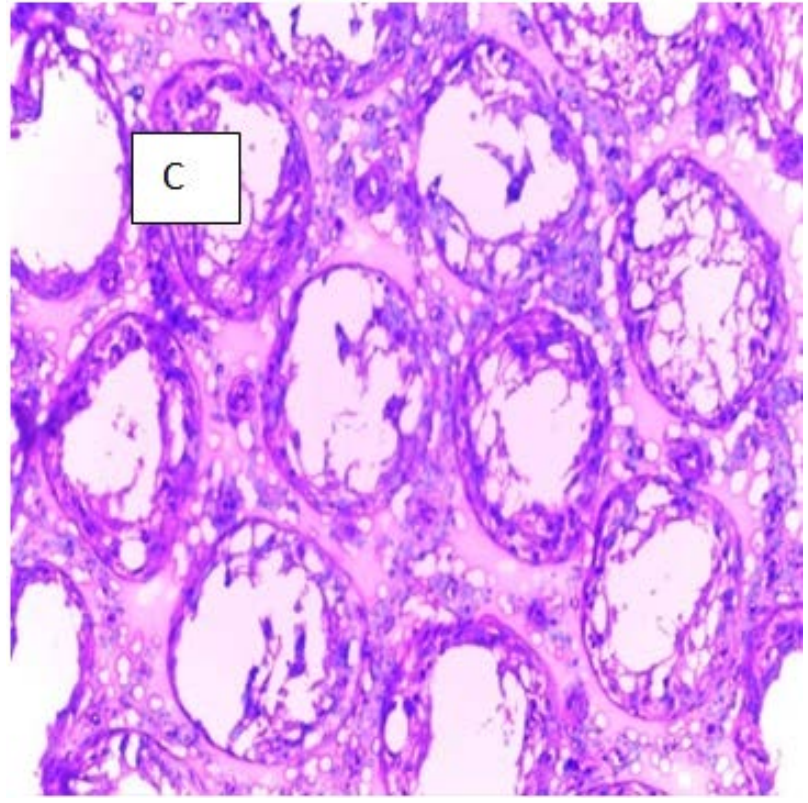

Photomicrograph C. The testis of rat treated with $22.8 / 5.8 \mathrm{mg} / \mathrm{kg}$ of $\mathrm{LPV} / \mathrm{r}$ for 8 weeks showing thick basement membrane of the seminiferous tubules with loss of maturation stages of spermatocytes and focal cytolysis (H\& Ex 400)

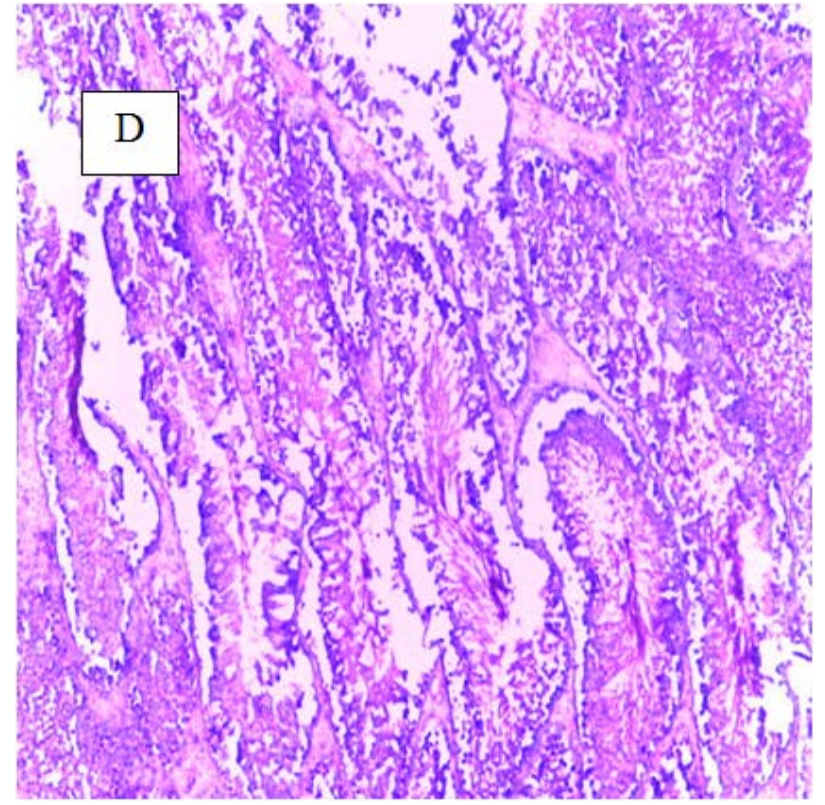

Photomicrograph D. the testis of rat treated with combined doses of SMX/TMP +LPV/r for 8 weeks showing thick basement membrane of the seminiferous tubules with loss of maturation stages of spermatocytes, focal cytolysis and edematous interstitium infiltrated by mononuclear inflammatory cells. (H\&E x400)

Table 1. Effects of lopinavir/ritonavir, sulfamethoxazole/trimethoprim and their combination on testicular weight (gram) in male albino rats

\begin{tabular}{lccc}
\hline DOSE & WK2 & WK4 & WK6 \\
\hline CONTROL & $2.12 \pm 1.17$ & $2.16 \pm 2.04$ & $2.15 \pm 1.14$ \\
SMX/TMP $(22.4 / 4.6 \mathrm{mg} / \mathrm{kg})$ & $2.00 \pm 0.07$ & $2.01 \pm 2.17$ & $2.11 \pm 0.13$ \\
LPV/r (22.8/5.8mg/kg) & $2.06 \pm 1.03$ & $2.00 \pm 2.24$ & $2.06 \pm 1.18$ \\
SMX/TMP +LPV/r) & $2.00 \pm 0.26$ & $2.03 \pm 0.15$ & $2.12 \pm 1.33$ \\
\hline
\end{tabular}

Table 2. Effects of lopinavir/ritonavir, sulfamethoxazole/trimethoprim and their combination on kidney malondialdehyde (n mole/gram tissue) in male albino rats

\begin{tabular}{|c|c|c|c|c|}
\hline DOSE & WK2 & WK4 & WK6 & WK8 \\
\hline CONTROL & $6.49 \pm 3.13$ & $6.53 \pm 2.27$ & $6.51 \pm 3.12$ & $6.50 \pm 0.23$ \\
\hline SMX/TMP (22.4/4.6mg/kg) & $6.82 \pm 1.15$ & $7.23 \pm 2.14$ & $10.5 \pm 2.07 *$ & $13.26 \pm 2.26 *$ \\
\hline $\mathrm{LPV} / \mathrm{r}(22.8 / 5.8 \mathrm{mg} / \mathrm{kg})$ & $7.14 \pm 1.18$ & $8.02 \pm 0.13$ & $8.54 \pm 3.14$ & $12.54 \pm 2.16^{*}$ \\
\hline SMX/TMP +LPV/r) & $7.51 \pm 1.24$ & $8.1 \pm 2.06$ & $11.10 \pm 0.06^{*}$ & $15.5 \pm 3.27^{*}$ \\
\hline
\end{tabular}

Results are expressed as mean \pm SEM, $\mathrm{n}=5$, the superscript $\left(^{*}\right)$ means significant difference with respect to the control at $p<0.05(\mathrm{ANOVA})$.

Table 3. Effects of lopinavir/ritonavir, sulfamethoxazole/trimethoprim and their combination on testis superoxide dismutase (units/gram protein) in male albino rats

\begin{tabular}{lccc}
\hline DOSE & WK2 & WK4 & WK6 \\
\hline CONTROL & $10.1 \pm 2.40$ & $10.4 \pm 1.23$ & $10.1 \pm 3.12$ \\
SMX/TMP $(22.4 / 4.6 \mathrm{mg} / \mathrm{kg})$ & $10.3 \pm 1.15$ & $8.50 \pm 2.06$ & $10.2 \pm 3.31$ \\
LPV/r (22.8/5.8mg/kg) & $9.83 \pm 2.07$ & $9.52 \pm 4.06$ & $5.01 \pm 2.11^{*}$ \\
SMX/TMP +LPV/r) & $9.01 \pm 2.02$ & $8.53 \pm 1.01$ & $6.23 \pm 3.05^{*}$ \\
\hline
\end{tabular}

Results are expressed as mean \pm SEM, the superscript $(*)$ means significant difference with respect to the control at $p<0.05$ (ANOVA).

Table 4. Effects of lopinavir/ritonavir, sulfamethoxazole/trimethoprim and their combination on sperm count (million/mil) in male albino rats

\begin{tabular}{|c|c|c|c|c|}
\hline DOSE & WK2 & WK4 & WK6 & WK8 \\
\hline CONTROL & $61.3 \pm 2.12$ & $65.1 \pm 4.38$ & $63.5 \pm 3.14$ & $65.5 \pm 1.27$ \\
\hline SMX/TMP (22.4/4.6mg/kg) & $63.4 \pm 3.16$ & $58.3 \pm 2.11$ & $35.1 \pm 2.20 *$ & $30.3 \pm 1.29 *$ \\
\hline LPV/r (22.8/5.8mg/kg) & $60.4 .00 \pm 1.21$ & $56.2 \pm 3.18$ & $53.7 \pm 4.21$ & $38.2 \pm 2.11 *$ \\
\hline $\mathrm{SMX} / \mathrm{TMP}+\mathrm{LPV} / \mathrm{r}$ & $59.4 \pm 3.14$ & $40.3 \pm 1.01^{*}$ & $30.5 \pm 2.21 *$ & $27.5 \pm 1.00 *$ \\
\hline
\end{tabular}

Results are expressed as mean \pm S.E.M, $\mathrm{n}=5$, the superscript $(*)$ means significant difference with respect to the control at $p<0.05(\mathrm{ANOVA})$. 
Table 5. Effects of lopinavir/ritonavir, sulfamethoxazole/trimethoprim and their combination on sperm motility (\%) in rats

\begin{tabular}{lccc}
\hline DOSE & WK2 & WK4 & WK6 \\
\hline CONTROL & $66.1 \pm 2.14$ & $68.0 \pm 0.23$ & $68.2 \pm 0.07$ \\
SMX/TMP $(22.4 / 4.6 \mathrm{mg} / \mathrm{kg})$ & $65.2 \pm 2.08$ & $55.4 \pm 2.16$ & $37.2 \pm 1.14^{*}$ \\
LPV/r (22.8/5.8mg/kg) & $64.2 \pm 1.13$ & $58.3 \pm 0.16$ & $35.2 \pm 0.21^{*}$ \\
SMX/TMP +LPV/r & $59.2 \pm 2.04$ & $54.3 \pm 0.06$ & $34.6 \pm 1.11^{*}$ \\
\hline
\end{tabular}

Results are expressed as mean \pm S.E.M, $\mathrm{n}=5$, the superscript $\left({ }^{*}\right)$ means significant difference with respect to the control at $p<0.05(\mathrm{ANOVA})$.

Table 6. Effects of lopinavir/ritonavir, sulfamethoxazole/trimethoprim and their combination on sperm morphology (\%) in rats

\begin{tabular}{lccc}
\hline DOSE & WK2 & WK4 & WK6 \\
\hline CONTROL & $14.7 \pm 3.15$ & $16.4 \pm 2.33$ & $15.5 \pm 3.45$ \\
SMX/TMP $(22.4 / 4.6 \mathrm{mg} / \mathrm{kg})$ & $17.3 \pm 2.08$ & $19.5 \pm 2.16$ & $22.2 \pm 1.14 *$ \\
$\mathrm{LPV} / \mathrm{r}(22.8 / 5.8 \mathrm{mg} / \mathrm{kg})$ & $15.3 \pm 1.13$ & $16.2 \pm 0.16$ & $35.6 \pm 0.08 *$ \\
SMX/TMP +LPV/r & $18.1 \pm 2.04$ & $18.7 \pm 0.06$ & $30.5 \pm 1.09 *$ \\
\hline
\end{tabular}

Results are expressed as mean \pm S.E.M, $\mathrm{n}=5$, the superscript $\left({ }^{*}\right)$ means significant difference with respect to the control at $p<0.05(\mathrm{ANOVA})$.

\section{Discussion}

Spermatogonia are sensitive to chemical agents interfering with DNA replication because these cells go through several mitotic divisions. Considering the pivotal involvement of spermatozoan functions in fertilization, measuring multiple sperm parameters, evaluation of testicular weight and oxidative stress markers could attest to drug induced testicular damage $[35,36]$. This study, therefore evaluates the effects of co-administered SMX/TMP+ LPV/r on semen parameters, testicular oxidative stress markers and architecture. Researchers have shown that change in organ weight induced by a chemical agent is a maker of its toxicity [37]. In this study it was noted that treatment with single and combined doses of these agents didn't produce any significant change in testicular weight. Malondialdehyde is the major oxidative product of the peroxidation of polyunsaturated fatty acids. This makes an increase in MDA level observed in this study, in animals treated with single doses of these agents a sign of lipid peroxidation induced by these agents [38,39]. Concurrent use of these agents may not be deleterious to testicular function due to lack of synergistic increase in testicular MDA level when they were co-administered as observed in this study. Testis contains antioxidant enzymes which include SOD to protect itself from the hazardous effects of oxidative attack. In this study decrease in SOD level was observed when single doses of these agents were administered which is in agreement with some reported observations [40,41]. This could be attributed to increased testicular oxidative stress via the generation of ROS $[42,43]$. Co- administration of these agents may not be toxic to testicular function due to lack of significant synergistic decrease in SOD level when these agents were co-administered as observed in our study. Documented evidence showed that decrease in sperm count is an important indicator of male infertility [44]. Decrease in sperm count associated with exposure to LPV/r agrees with some reported observations [45,46], also SMX/TMP induced decrease in sperm count observed in this study has been reported by some authors [47]. In the absence of significant synergistic decrease in sperm count when these agents were co-administered the concurrent use of these agents may be safe on testicular function. Decrease in sperm count by these agents may be attributed to damage to leydig cells and seminiferous tubules responsible for testosterone and sperm production respectively [48].

Decrease in sperm motility often indicates chemical-induced testicular toxicity, and in men; defect in sperm motility causes untreatable infertility or subinfertility $[49,50]$. Decrease in sperm motility observed with LPV/r treatment in this work is in agreement with reports from some quarters $[51,52]$ while decrease in sperm motility observed in SMX/TMP treated animals is also supported by some observations [53]. Observation in this study shows that the co-administration of these agents may not have deleterious effect on sperm motility. Decrease in sperm motility noted with these agents could be attributed to their interference with energy production required for sperm motility [54] and damage to mitochondria which are component of spermatozoa required for energy production to sustain sperm motility [55,56,57].

Semen morphology as measured according to strict criteria appears to be the most informative semen measurement for discriminating between fertile and infertile men [58]. Increase in abnormal sperm morphology observed with single doses of $\mathrm{LPV} / \mathrm{r}$ and SMX/TMP is in agreement with reports from some quarters [59,60,61]. Concurrent use of these agents may be safe on sperm morphology due to insignificant synergistic increase in abnormal sperm morphology when they were co-administered. Observed decrease in sperm morphology in this study could be attributed to inhibition of meiosis of primary spermatocytes to matured sperm cells or direct destruction of sperm cell [62]. Observed abnormal testicular histopathological changes in LPV/r treated animals is consistent with some reported observations [63]. Similar abnormal testicular histopathological changes were noted in SMX/TMP treated animals with more pronounced effects when coadministered with LPV/r. Histopathological changes observed in this study may be associated with testicular oxidative stress leading to damage of testicular micro molecules $[64,65]$. This could be correlated with observed elevated MDA level and decreased SOD level in this study.

\section{Conclusion}

In this study, observed decrease in semen quality, testicular superoxide dismutase and increase in 
malondialdehyde level correlates with observed testicular histopathological changes. The concurrent use of these agents may be safe on male reproductive function due to lack of synergistic effects on all evaluated parameters when these agents were co- administered.

\section{References}

[1] Purvis K, Christiansen E. 1992. Male infertility: Current concepts. Ann. Med. 24: 259-272.

[2] Rabin DS, Qadeer U, Steir VE. 1996. A cost and outcome model of fertility treatment in a managed care environment. Fertil Steril. 66 (6): 896-903.

[3] Thonneau P, Marchand S, Tallec A, Ferial ML, Ducot B, Lansac J, et al. 1989. Incidence and main causes of infertility in a resident population $(1,850,000)$ of three French regions (1988-1989) Hum Reprod. 6(6):811-6.

[4] Singh K, Jaiswal D. 2011. Human male infertility: a complex multifactorial phenotype. Reprod Sci. 18 (5):418-25.

[5] Natali A, Turek PJ. 2011.An assessment of new sperm tests for male infertility. Urology. 77 (5): 1027-34.

[6] Cardona Maya WD, Berdugo Gutierrez JA, de los Rios J, Cadavid Jaramillo AP. 2007. Functional evaluation of sperm in Colombian fertile men. Arch Esp Urol. 60: 827-31.

[7] Rodriguez-Martinez H. 2003. Laboratory semen assessment and prediction of fertility: still utopia? Reprod Domest Anim, 38: 312318.

[8] Brooks JD. Anatomy of the lower urinary tract and male genitalia. In: Kavoussi LR, Novick AC, Partin AW, Peters CA, Wein AJ, eds. Campbell’s Urology. 9th ed. Saunders Elsevier; 2007: 38-80.

[9] Sharpe RM. Paracrine control of the testis. Clin Endocrinol Metab. 1986; 15 (1):185-207.

[10] Tanrikut C, Schlegel PN. 2007. Antidepressant-associated changes in semen parameters. Urology 69: 185.e5-185.e7.

[11] Hayashi T, Yoshida S, Yoshinaga A, Ohno R, Ishii N, Yamada T. 2005. Improvement of oligoasthenozoospermia in epileptic patients on switching anti-epilepsy medication from sodium valproate to phenytoin. Scand J Urol Nephrol. 39(5):431-2.

[12] Sham, H. L., Kempf, D. J., Molla, A. 1998. ABT-378, a highly potent inhibitor of the human immunodeficiency virus protease. Antimicrobial Agents and Chemotherapy, 42, 3218-24.

[13] Oldfield V, Plosker G. Lopinavir/Ritonavir. 2006. A review of its use in the management of HIV infection. Drugs, 9:1275-1299.

[14] Chandwani A, Shutter J. 2008. Lopinavir/ritonavir in the treatment of HIV-1 infection: a review. Ther. Clin. Risk Man. 4:1023-1033

[15] Elias, A. Brambaifa, N Oputiri. D and Oru-Bo P. G. 2013 Antiretroviral toxicity and oxidative stress American Journal of Pharmacology and Toxicology, 8 (4): 187-196.

[16] Wensing, A., van Maarseveen. N and Nijhuis M. 2010. Fifteen years of HIV protease inhibitors: Raising the barrier to resistance. Antiviral Res. 85: 59-74.

[17] Palella FJ, K. M. Delaney A. C. Moorman 1998. Declining morbidity and mortality among patients with advanced human immunodeficiency virus infection. HIV Outpatient Study Investigators. N Engl J Med.338: 853-860.

[18] Then R, P. Angehm, 1976, Nature of the bactericidal action of sulfonamides and trimethoprim, alone and in combination. J Infect Dis, 128: S498-501.

[19] Justice AC. 2006. Prioritizing primary care in HIV: comorbidity, toxicity, and demography. Top HIV Med. 14(5): 159-63.

[20] Vilar F, S. Khoo, T. TWalley. 1999. The management of Pneumocystis carinii pneumonia. Br J Clin Pharmacol. 47 (6):6059.

[21] Hargraves C. A Rogers S, Hill F, Rahman F, Howell RS, Homa ST. 1998. Effects of Cotrimoxazole, erythromycin, amoxicillin tetracycline and chlroquine on sperm function in vitro Human Repro. 13;17, 1878-1886.

[22] Schrooten, W., Colebunders, R., Youle, M., 2001. Sexual dysfunction associated with protease inhibitors containing highly active antiretroviral treatment. AIDS, 15, 1019-1023.

[23] Olayemi F. 2010. A review on some causes of male infertility. Afri. Jour. of Biotec Vol 9: 20, 2834-2842.

[24] Yániz JL, Marco-Aguado MA, Mateos JA, Santolaria P. 2010. Bacterial contamination of ram semen, antibiotic sensitivities, and effects on sperm quality during storage at $15^{\circ} \mathrm{C}$. Anim Reprod Sci. 122 (1-2): 142-9.

[25] Kielhofner, M A. 1990. Trimethoprim- Sulfamethoxazole: Pharmacokinetics, Clinical Uses, and Adverse Reactions Tex Heart Inst J. 17(2): 86-93.

[26] Hull M. W, M. Harris, V. Lima, et al. 2009. Lopinavir/ritonavir pharmacokinetics in a substitution of high-dose soft-gelatin capsule to tablet formulation. J Clin Pharmacol. 49: 155-61

[27] Reyskens KMSE, T. L. Fisher, J. C. Schisler, O’Connor WG, Rogers AB, 2013. Cardio-Metabolic Effects of HIV Protease Inhibitors (Lopinavir/ Ritonavir), PLoS ONE, 8(9): e73347.

[28] Nathiya. S, and Nandhini.A, 2014 Evaluation of antioxidant effect of Salacia oblonga against aluminum chloride induced visceral toxicity in albino rats Int J Basic Clin Pharmacol. 3(2):315-319.

[29] Draper H. H, M. Hadley. 1990. Malondialdehyde determination as index of lipid peroxidation. Methods Enzymol. 186: 421-431.

[30] Beauchamp C, I. Fridovich. 1971. Superoxide dismutase: improved assays and an assay applicable to acryl amide gels. Anal. Biochem. 44: 276-287.

[31] World Health Organization (WHO). WHO laboratory manual for the examination of human semen and sperm-cervical mucus interaction. 4 th ed. United Kingdom: Cambridge University Press; 1999.

[32] Wyrobek AJ, Bruce WR. 1975. Chemical induction of sperm abnormalities in mice. Proc Natl Acad Sci USA. 72(11): 44254429.

[33] Narayana K, D’souza UJ, SeetharamaRao KP. 2002. Ribavirininduced sperm shape abnormalities in Wistar rat. Mutat Res. 513(1-2): 193-196.

[34] Drury, R.A.B., E.A. Wallington and R. Cameron, 1967. Carleton's Histological Techniques. 4th Edn., Oxford University Press, NY. USA, pp: 279-280.

[35] Ahtiainen M, Toppari J, Poutanen M, Huhtaniemi I. 2004. Indirect Sertoli cell-mediated ablation of germ cells in mice expressing the inhibin-alpha promoter/herpes simplex virus thymidine kinase transgene. Biol Reprod. 71(5): 1545-1550.

[36] Boe-Hansen GB, Morris ID, Ersbøll AK, Greve T, Christensen P. 2005. DNA integrity in sexed bull sperm assessed by neutral Comet assay and sperm chromatin structure assay. Theriogenology. 63(6): 1789-1802.

[37] Elias A. and B. Nelson, 2012. Toxicological effect of ciprofloxacin on testicular function of male guinea pigs, Asian Jour. Bio Sci. 3(2); 384-390.

[38] Ogbuehi,I, E, Adikwu and D. Oputiri. 2014. Effect of Acalypha wilkesiana MuellArg Leaf Extract on the Oxidative Indices, Liver Enzymes and Liver Integrity of Rats Infected with Plasmodium berghei British Journal of Pharmacology and Toxicology. 5(2): 68-74, 2014.

[39] Adaramoye, O. 2012 Studies on the toxicological effect of nevirapine, an antiretroviral drug, on the liver, kidney and testis of male Wistar rats. Source: A. Human \& Experimental Toxicology Volume, 31 (7); 676-685.

[40] Olufadekemi YR, Kunle- Alabi SB, Gbadegesin Awobayo F. O. 2007. Impart of alpha tocopherol on metronidazole and tetracycline induced alterations in reproductive activities of male reproductive activities of male Albino rats Jour. of Biol. Sci. 2007; 7; 41-46.

[41] Adaramoye. O. A, Akanni, O. O. Farombi, E. O, 2012. Nevirapine induces testicular toxicity in Wistar rats: reversal effect of kolaviron (biflavonoid from Garcinia kola seeds) Journal of Basic and Clinical Physiology and Pharmacology. 24, (4) 313-320.

[42] Chitra KC, Latchoumycandane C, Mathur PP. 2003. Induction of oxidative stress by bisphenol A in the epididymal sperm of rats. Toxicology. 185:119-27.

[43] Fujii J, Iuchi Y, Matsuki S, Ishii T. 2003. Cooperative function of antioxidant and redox systems against oxidative stress in male reproductive tissues. Asian J Androl. 5: 231-42.

[44] Kumar SG, Narayana K, Bairy KL, D’souza UJ, Samuel VP, Gopalakrishna K. 2006. Dacarbazine induces genotoxic and cytotoxic germ cell damage with concomitant decrease in testosterone and increase in lactate dehydrogenase concentration in the testis. Mutat Res. 607(2): 240-252.

[45] Dondero F, Rossi T, D’Offizi G, Mazzilli F, Rosso R, Sarandrea N, Pinter E, Aiuti F. 1996. Semen analysis in HIV seropositive men and in subjects at high risk for HIV infection. Hum Reprod. 11: 765-768.

[46] Nicopoullos JD, Almeida PA, Ramsay JW, Gilling-Smith C. 2004. The effect of human immunodeficiency virus on sperm parameters 
and the outcome of intrauterine insemination following sperm washing. Hum Reprod. 19: 2289-2297.

[47] Lange, D. and Schirren, C. 1974. Studies on the influence of trimethoprim/ sulfamethoxazole on the quality of sperm in andrologic patients and a contribution to the pharmacological testing of a drug on the spermatogenic activity of the testis. $\mathrm{Z}$. Hautkr : 49, 863-878.

[48] Abd-Allah AR, Aly HA, Mustafa AM, Abdel-Aziz AA, 2002. Hamada FM. Adverse testicular effects of some quinolone members in rats. Pharmacol Res. (41): 211-219.

[49] Khaki A, Heidari M, Ghaffari Novin M, Khaki AA. 2008. Adverse effect of ciprofloxacin on testes apoptosis and sperm parameters in rats. IJRM. 6(2): 71-76.

[50] Acacio BD, Gottfried T, Israel R, Sokol RZ. 2000. Evaluation of a large cohort of men presenting for a screening semen analysis. Feril Steril. 73(3): 595-597

[51] Crittenden JA, Handelsman DJ, Stewart GJ. 1992. Semen analysis in human immunodeficiency virus infection. Fertil Steril. 57: 1294-1299.

[52] Dulioust E, Du AL, Costagliola D, Guibert J, Kunstmann JM, Heard I, Juillard JC, Salmon D, Leruez-Ville M, Mandelbrot L, Rouzioux C, Sicard D, Zorn JR, Jouannet P, De Almeida M. 2002. Semen alterations in HIV-1-infected men. Hum Reprod. 17: 2112 2118.

[53] White IG. 1954. The toxicity of some antibacterials for bull, ram, rabbit and human spermatozoa. Aust. J. Exp. Biol. Med. Sci 32, 41-48.

[54] Elias A. and B. Nelson 2012. Toxicological effect of perfloxacin on testicular function of male guinea pigs Asian Jour. Bio. Sci. 3(1); 28-33.

[55] White DJ, Mital D, Taylor S, St John JC. 2001. Sperm mitochondrial DNA deletions as a consequence of long term highly active antiretroviral therapy. Aids. 15: 1061-1062.

[56] Casula M, Weverling GJ, Wit FW, Timmermans EC, Stek M Jr, Lange JM, et al. 2005. Mitochondrial DNA and RNA increase in peripheral blood mononuclear cells from HIV-1-infected patients randomized to receive stavudine-containing or stavudine- sparing combination therapy. J Infect Dis, 192: 1794-1800.

[57] van Leeuwen E, Wit FW, Repping S, Eeftinck Schattenkerk JKM, Reiss P, van der Veen F, Prins JM. 2008. Effects of antiretroviral therapy on semen quality. AIDS. 22: 637-642.

[58] Cuzick DS, Overstreet J.W, Factor Litva PK, Brazil CK, et al., 2001. Sperm morphology, motility and concentration in fertile and infertile men N.Engl. Med. 345; 1388-1393.

[59] Robbins WA, Witt KL, Haseman JK, Dunson DB, Troiani L, Cohen MS, 2001. Antiretroviral therapy effects on genetic and morphologic end points in lymphocytes and sperm of men with human immunodeficiency virus infection. J Infect Dis 2001; 184: 127-135.

[60] Toovey S., Hudson E. Hendry WF, and Levi AJ. 1981. Sulfasalazine and male infertility reversibility and possible mechanism Gut. 22: 445-451.

[61] Alonso. V. Linares V. Belles M. Albina ML, Sirvent JJ. 2009. Sulfasalazine induced oxidative stress; Apossible mechanism of male infertility. Repro. Tox. 27; 35-40.

[62] Elias A. and B. Nelson 2012. Subchronic evaluation of ciprofloxacin and perfloxacin on spermatic parameters of male guinea pigs Asian Jour. Bio. Sci. 3(2); 595-601.

[63] Chris-Ozoko LE, Charity AA, Ekundina VO. 2013. Histomorphological effect of zidovudine on the testes of adult male wistar rats (rattus novegicus). J Basic Clin Reprod Sci; 2:736

[64] Lewis W, Day BJ, Copeland WC. Mitochondrial toxicity of NRTI antiviral drugs: an integrated cellular perspective. Nat Rev Drug Discov. 2003; 2: 812-822

[65] Pollman, M.J., T. Yamada, M. Horiuchi and G.H. Gibbons. 1996 Vasoactive substances regulate vascular smooth muscle cel apoptosis: countervailing influences of nitric oxide and angiotensin II,” Circulation Research; 79 (4)748-756, 1996. 